Edith Cowan University

Research Online

Research outputs 2014 to 2021

$1-1-2019$

Performing 'teacher': Exploring early career teachers' becomings, work identities and the [mis-]use of the professional standards in competitive educational assemblages

\author{
Kirsten Lambert \\ Edith Cowan University \\ Christina Gray \\ Edith Cowan University
}

Follow this and additional works at: https://ro.ecu.edu.au/ecuworkspost2013

Part of the Education Commons

10.1080/14681366.2019.1663247

This is an Accepted Manuscript of an article published by Taylor \& Francis in Pedagogy, Culture \& Society on 9 September 2019, available online: http://www.tandfonline.com/10.1080/14681366.2019.1663247

Lambert, K., \& Gray, C. (2019). Performing 'teacher': exploring early career teachers' becomings, work identities and the [mis-] use of the professional standards in competitive educational assemblages. Pedagogy, Culture \& Society, 28(4) 501-523. https://doi.org/10.1080/14681366.2019.1663247

This Journal Article is posted at Research Online.

https://ro.ecu.edu.au/ecuworkspost2013/8414 


\title{
Performing 'teacher': Exploring early career teachers' becomings, work identities and the [mis-]use of the professional standards in competitive educational assemblages.
}

Research Article

Kirsten Lambert and Christina Gray

School of Education, Edith Cowan University, Mt Lawley, Western Australia.

\begin{abstract}
This paper explores the relationship between early career teachers' (ECTs) work identities, neoliberal education assemblages, and mandated professional standards. The task of supporting and retaining beginning teachers has received considerable attention in recent years in the face of alarming rates of teacher attrition internationally. The study, undertaken in Western Australia, explores how ECTs construct identities in response to competitive educational discourses, high levels of individual stress, insecure employment, excessive work-loads and limited formal support. The Australian Professional Standards are an example of 'organisational learning' that aims to support ECTs. However, our research suggests that in practice a managerial 'tick the box' approach to addressing the Standards renders them ineffective. We consider how embodied teacher identities are moulded in neoliberal secondary schools through concepts of performativity. This paper concludes that the performing arts can offer creative, collaborative and impassioned approaches to encouraging authentic teacher identities to support and retain ECTs.
\end{abstract}


Keywords: performing arts teachers, early career teachers, attrition, work identity, professional standards, neoliberalism

\section{Introduction}

The teacher before me just up and quit. It was her first year in the job and she decided after four weeks, 'I'm not doing this'. And she left.

(Annabelle, ECT)

On December 28, 2018 The Wall Street Journal featured the troubling headline 'Teachers Quit Jobs at Highest Rate on Record' (Hackman and Morath, 1). In the United Kingdom (UK) in 2018, The Guardian headlined with a similar story: 'Burned out: why are so many teachers quitting?' (Tapper 2018). Likewise, the Australian media are describing the 'outflux' of teachers in Australian schools as a 'Recruitment Crisis in Schools' (Tickle 2018, 1). Indeed, the situation appears bleak for early career teachers (ECTs). In Australia, 50 percent of ECTs leave within five years of graduating (Stroud 2018) and this statistic is echoed across the western world. As a result, various stop-gap measures such as 'one-year paid sabbaticals' are being offered to those who stay in the profession to stop the 'haemorrhaging' of teaching staff (Slawson and Adams 2018, 1). In the UK, the discursive nomenclature labels the situation an education 'crisis' with just under 40000 teachers resigning in 2016 resulting in a ‘30 000 classroom-teacher shortfall’ in 2018 (Tapper 2018, 1).

The gig economy?

Some contemporary theorists suggest that this is because ECTs are finding traditional organisational structures and nine-to-five schedules increasingly obsolete, preferring the 
flexibility of the so-called 'gig' economy ${ }^{1}$. According to this line of thought 'millennials' are abandoning traditional employment 'in favour of working independently on a task-by-task basis' (Smith 2016, 3). For example, Smith (2016) states that, 'workers, particularly millennials, are expressing an increasing demand for flexible and autonomous work' (3). Moreover, according to Schawbel (2013) almost 50 percent of millennials 'choose workplace flexibility over pay' (18). Other theorists highlight that the benefits of the gig economy are not equally shared (Wright, Wailes, Bamber and Lansbury 2017). They suggest that 'sharing economy' entities such as Uber are merely the latest iteration of companies seeking to enact neoliberal industrial relations abuses (Zwick 2018, 679). Regardless of the way one envisions the gig economy, it is of grave concern to us in the field of teacher education that students who spend four years at university (not to mention thousands of dollars) find the profession so intolerable that they leave within the first year. According to Stroud (2018) after a short period of time in the classroom, many ECTs come to the conclusion that 'anything is better than teaching' - and this is not hyperbole. Stroud notes that the many ECTs leave teaching to become 'bloggers, publicans and footballers' because the energy and enthusiasm they began with was 'drained away' through lack of support (Stroud 2018, 2).

\section{Literature Review}

Much recent research has explored ECT attrition (Borman and Dowling 2008; Clandinin et al. 2015; Dupriez, Delvaux, and Lothaire 2016; Mason and Matas 2017). Dupriez, Delvaux, and Lothaire's (2016) research found that the exit rates amongst ECTs are much higher in secondary education than at pre-school and primary levels. High stress combined with a lack of support and professional autonomy are to blame according to recent research (McDowall

\footnotetext{
${ }^{1}$ The gig economy is characterised by rising trends in par-time short-lived employment. In a gig economy, workers either choose to or are compelled to utilise their skills to pick up and fulfil gigs rather than gain fulltime traditional employment. Proponents for the gig economy suggest that it offers workers more flexibility, satisfaction, and creativity in their work (Golden, Henley and Lambert 2013).
} 
and Kinman 2017). For example, Tapper (2018) stated that 'overwork and lack of support are driving teachers across England out of the profession much faster than they can be replaced' (1). Martin and Mulvihill (2016) noted that this exodus of teachers was not because they were ill-suited or unprepared for teaching: 'Well-prepared and successful teachers are exiting the profession at alarming rates in several places in the world, including the United States, Canada, and Australia' (91). Djonko-Moore (2016) supports these findings by demonstrating that school culture and teachers' perceptions of school culture facilitates teacher attrition. Interestingly, the international literature on work environment data indicate that a school's socio-economic level does not foreshadow teacher attrition (Dupriez et al. 2016). Rather, they found a close relationship between employment conditions and attrition during the first year in the profession. They argue that these results require 'paying greater attention to the institutional conditions of career management in future research' and the need to 'explore varied professional identities, which can flourish in such a variety of schools' (456).

The literature on teacher retention in the past decade depicts a move away from a 'narrow, technical, and fixed goal-oriented framework' of understanding beginning teachers 'towards reconceptualizing the development of becoming a new teacher as a process' (Long et al. 2012, 22). Rippon and Martin (2006) examined the processes whereby beginning teachers negotiate their identities as teachers within school cultures. Their study emphasised the emotional need for beginning teachers to belong and to be seen as a teacher by colleagues was as important as professional development. One obstacle to 'fitting in' is a school culture that is individualistic. Smethen (2007) found that teachers were committed to teaching management created school spaces that facilitated constructing a resilient teacher identity where they felt they could make a difference in children's lives. Lieberman and Pointer-Mace (2010) explored how mentoring was useful for shaping beginning teachers' identities. 
Tuytens and Devos (2010) criticised using a framework of standardised identities based on external constructions of the 'good' teacher. Likewise, Clandinin et al. (2015) shifted the focus of teacher attrition research from individual or contextual factors to a more holistic exploration of the lives of beginning teachers and how we could not just retain them but sustain them.

When exploring teacher attrition in Australia, Mason and Matas (2015) suggest the field is in need of a new theoretical model that acknowledges the complex nature of teacher attrition and encourage researchers to explore this proposed conceptual framework.

Teacher attrition is a complex phenomenon, a product of the intersection of elements from social capital, human capital, positive psychological capital and structural capital...It is our belief that without strong human, social, structural and positive psychological capital, even teachers starting with high levels of human capital will be unable to meet their full potential to develop professionally and become better teachers in their educational contexts. (44)

Many education researchers have utilised Deleuze and Guattari's materialist conceptualisations of embodiment and becoming because they allow for heterogeneity and multiplicity (see Ringrose 2014; Hickey-Moodey, 2015; Lambert et., 2017). This lens is rhizomatic (Deleuze and Guatarri, 1987 [2012]) in that it connects a variety of different assemblages to subjectivity and the process of becoming a teacher. Assemblages are the intersections and connections between bodies, technology, discourse and buildings. Thus, a teacher's subjectivity is an active interplay between the embodied and embedded self, others, schools and hegemonic ideas. 
It is at this intersection of the debate that our research seeks to add to the discourse.

Specifically, we propose a new-materialist embodied posthumanist exploration of the process of ECT work identity formation (becoming). Specifically, we begin by exploring ECT's experiences of the first years of teaching. What is it like to be a beginning performing performing arts teacher in the $21^{\text {st }}$ century? What constrains ECTs and what enables them to flourish? In this way we are building on the existing body of knowledge, continuing the journey of mapping teacher subjectivity with the aim to improve the retention of ECTs in the future, and for the education of our next generation. This study is a rope woven of three threads. Firstly, we examine theories of flourishing, mastery, identity and becoming in the context of subjective materiality. Secondly, we foreground the influence of competitive neoliberal educational cultures on teacher identity formation. Our final thread takes as our focus ECTs embodiment of teacher work identities in relation to the AITSL Professional Standards (AITSL 2011).

\section{Flourishing at work - mastery and identity}

There has been significant interest amongst organisations and researchers ascertaining the conditions that promote positive work experiences (Chiva 2017; Jha et al. 2010; Organ, 1988). Much recent research into happiness at work and subjective well-being suggests that this positive affect requires a mix of feeling competent (organisational learning capability attaining mastery/confidence); feelings of belonging to an organistion as a whole (work culture/identity); and harmonising this identity with a sense of self (Salas-Vallina, Alegre and Fernandez 2017). Moreover, recent studies into creative effort and subjective well-being at work concluded that 'Employers and managers who wish to improve their workers' productivity should create a work environment where the workers feel they can invest more 
creative effort' (Sherman and Shavit 2018, 2065). Furthermore, subjective well-being or happiness raises organisational citizenship behaviour ${ }^{2}$ ) which is the willingness of an employee to be engaged in extra-curricular activities outside of work hours. This construct goes beyond traditional measures of job performance and reveals a type of behaviour that refers to positive contributions, made by employees, that are not included in their job specifications. Moreover, it implies making efforts to help one's peers in an altruistic way (Salas-Vallina, Alegre and Ferandez 2017, 137).

We begin by exploring the first antecedent to happiness at work: feeling competent attaining mastery. Work mastery is self-evaluation of how well effort at work creates desirable work outcomes for the individual. In a recent study, work mastery was found to be the most important factor for the well-being of employees working in many professions (Foldal, Langvik and Saksvik-Lehouillier 2016). K. Anders Ericsson's (1993) empirical research into elite sports performance has popularly been (mis-) represented as the oft-quoted '10000 hour' rule of deliberate practice required to become an expert (see Ericsson 2013). Ignoring the inappropriateness of applying Ericsson's theoretical framework to education and teaching, for the sake of illustration, we will proceed. In teaching terms, this equates to just over seven years in the classroom (40 weeks in a school year $\mathrm{x}$ seven hours a day teaching $\mathrm{x}$ five days a week $=1400$ hours a year $\mathrm{x} 7.14$ years $=10000$ hours of practice). Regardless of how many hours it takes to 'master' teaching, it is clear that many teachers never reach the seven-year mark, or even one year. Moreover, mastery experiences — prior successes — build a robust basis for teacher efficacy while failure undermines it (Bandura 1997, 80). Teachers who believe that they are able to engage, support and manage students' learning and

\footnotetext{
${ }^{2}$ Organisational citizenship behaviour (OCB) is defined by Organ (1983) as the 'individual behaviour that is discretionary, not directed or explicitly recognised by the formal reward system, and that in the aggregate promotes the effective functioning of the organisation' (Organ, 1988, p.4).
} 
academic performance, even in difficult circumstances, have a sense of efficacy, referred to as teacher self-efficacy. Research shows that both teacher self-efficacy and teacher autonomy are associated with higher levels of commitment and a prolonged stay in the profession (Glickman and Tamashiro 1982; Malmberg, Hagger and Webster 2014). Thus, mastery is gained through repeated positive teaching experiences and their emotional and motivational affect.

Teacher agency stems from a history of successes and failures. Mastery experiences of past performance form a basis for concurrent self-evaluations, which in turn provide a basis for expectations of future success (Bong and Skaalvik 2003). The AITSL standards for teachers focus predominantly on competences for organising and structuring the learning environment, rather than the affective aspects of teaching. It has been suggested that more emphasis be given to affective, autonomy supportive and cognitively stimulating aspects of teaching, than focusing almost exclusively on classroom organisation and behaviour management (McNally Blake, Corbin and Gray 2008). Teacher self-efficacy is defined as 'teachers' belief or conviction that they can influence how well students learn, even those who may be difficult or unmotivated' (Guskey and Passaro 1994, 4). A sequence of mastery experiences gives rise to a higher sense of efficacy, while a series of failures will thwart the sense of self-efficacy (Bandura 1997, 80). A standards-centred discourse focuses on product rather than affect. A teacher's sense of self-efficacy is linked to the emergence of a revised self that has within it a new teacher identity, typically after 'several weeks of emotional turmoil and vulnerability' (McNally et al. 2008, 1470). The ECT is provisionally acquiring a new sense of identity, of teacher 'ontological security' (Giddens 1991, 36).

\section{Identity}


We believe that teacher identity construction is salient because it connects the human, social, psychological and structural aspects of being a teacher. Moreover, education policy is grounded in theories of the subject. Recent studies into psychological, social and organisational well-being note that cultivating and sustaining authentic work identities requires workers to synchronise and eventually harmonise their work experiences with a sense of self. This salience with one's work identity is characterised by 'behaving according to what one considers to be one's true self' - and that this self is a complex, multifaceted cognitive structure' (Gable and Haidt, 2005; Caza, Moss and Vough, 2018). It is at this juncture that we insert a dose of Deleuzian/Spinozan materialist philosophical understanding of the self.

This materialist understanding of the self, prioritises complexity, embodied materiality and movement over time. Teachers are embodied actors (particularly performing arts teachers) and any understanding of 'self' needs to be mediated through the lens of embodied subjects interacting with other embodied subjects, technologies, discourses and curricula. We believe that a Deleuzian (1987 [2012]) approach to subjectivity and becoming offers a generative, interconnected map of how teachers experience their first years in the classroom, which is a complex interplay of personalities, power and difference. Unlike scrutinising quantifiable stable objects, examining performing arts teaching, the free-flowing subjects within the room and the openness of the classroom itself (sans desks) requires a more nuanced approach to mapping teacher becomings. Moreover, it is not merely the classroom that teachers have to cope with. More often than not it is the culture, the educational discourses and the power-hierarchies that exist within the curriculum and schools themselves that ECTs interact with on a daily basis (Lambert, Wright, Currie and Pascoe, 
2017). Thus, a rhizomatic interconnected approach that takes into consideration the materially situated and intersectional nature of teacher subjectivity is preferred.

Teachers do not teach in a political vacuum. Neo-capitalist discourses have a tendency to individualise success and failure, however, when education systems are faced with significant trends on a global scale, we must consider wider contextual issues. Johnson and Down (2013) problematise attempts to solve the issue of teacher attrition that adopt a deficit perspective by focusing on individual teacher behaviour or lack of agency. They suggest that research must take into account the hyper-individualised cultural contexts in which ECTs work. Johnson and Down (2013), for example, suggest that 'what is lacking in the literature currently is an in-depth understanding of the interplay of personal and contextual factors around early career teachers' experiences' (530). Studies exploring ECTs identity construction have noted that the overwhelming demands of the profession in our current political climate, combined with a lack of collegiate support can result in high levels of attrition (Ado 2013; Johnson and Down, 2013; Nichols, Schutz, Rodgers and Bilica 2016; Trent 2015).

\section{The current political milieu}

The current educational climate is characterised by the meta-narrative of crisis, reform and competition. 'Education reform' is promised to solve the 'crisis in education' through 'improving teacher quality' and 'staying competitive' (McPhee and Savage 2014; Pyne 2014). Universities receive much of the blame for the so-called crisis because, according to former Australian Federal Education Minister Christopher Pyne, they produce graduate teachers who are 'not up to scratch' (Pyne 2014). In Australia the AITSL Professional Standards were implemented to improve teacher quality by providing teachers, 'with the 
knowledge, guidance and resources' to become 'excellent teachers' (AITSL 2011, 1). There has been much criticism of the reductionist, technical and instrumentalist impacts of the Australian Professional Standards for Teachers (Loughland and Ellis, 2016). Their aim is to regulate and standardise teacher practice through the utilisation of a common standards discourse. We argue in this article that what is required is a generative and creative approach to teaching that takes into consideration embodiment, creativity and multiplicity - rather than a reductionist discursive siloing of binary good and bad teaching. This will enable teachers to cope with the complexity, relationality and messiness of their burgeoning teacher identities. The notion of standardising teaching has been criticised for co-constructing 'the fantasy in which teaching and learning can be homogenised via a 'common understanding' and 'clarified' within a 'framework' (Clarke and Moore 2013, 488-489).

\section{Methodology and methods}

\section{The Study}

Our research project explored three interrelated questions: In what ways do beginning performing arts teachers experience the early years of teaching? What are the key issues and challenges experienced by beginning performing arts teachers? What are beginning performing arts teachers' perceptions of their readiness for teaching in relation to the Australian Professional Standards for teachers. To answer these questions, we interviewed 16 early career performing arts teachers from Western Australian independent/private and Catholic secondary schools. We were unable to gain permission to access government school teachers, however, the teachers who currently worked in Catholic or independent schools spoke of their experience in government schools. The participants had a variety of teaching 
experience with the average being one year. The semi-structured small group interviews with ECTs were audio-recorded over a period of three months in 2018. We analysed three rounds of in-depth interviews with six groups of ECTs who taught secondary drama and dance. The research participants were recruited by snowballing sampling (Walters, 2015). The interviews, which lasted between 55 minutes and 123 minutes, were transcribed after each round. Our encounter with the data followed what Mazzei (2014) describes as the process of 'reading-the-data-while-thinking-the-theory' (743). After one round of interviews we discussed the findings to identify emerging themes. Our fist interviews did not ask informants about identity directly; this theme emerged naturally from our discussions about the process the participants went through in the first year of teaching. After each wave of interviews, we revised our interview protocol so that subsequent interviews could further explore these themes.

\section{Findings}

The study reveals that ECTs develop teacher identities through a complex interplay of embodied, embedded and discursive connections between human and non-human entities. Our research is enriched through a critical, materialist posthumanist lens that examines subjectivity and becoming in the wider context of power in contemporary education. The theories of Braidotti (2013), Butler (1990, 2004) and Deleuze and Guattari (1994 [2012]) can be illuminating for researching emerging ECTs identities in contemporary secondary schools. We explore the corporeal manifestation of teacher 'becomings' and 'identities' rather than 'identity'. These terms account for multiplicity and can be seen as a process, whereas 'identity’ can be construed as fixed. Specifically, we map how ECTs negotiated hegemonic constructions of 'teacher' in neoliberal discourses and how these inform the AITSL 
standards. We also consider the impact our 'neoliberal culture of competitive performativity' has on moulding ECTs becomings (Ball, 2003, 219).

Henceforth, the first section of the article explores how Braidotti's understanding of subjectivity (2013) can contribute to previous studies of embodiment in relation to ECTs emerging identities. Second, we use the work of Deleuze and Guattari to shed light on subjectivity, materiality and transformation and how these can be used to map teachers' becomings. The third section examines how neoliberalism impacts ECTs subjectivities through their connection to the AITSL standards through Foucault's concept of governmentality (1977). Butler's concept of performativity $(1990,2004)$ is also used to explore the repetitive nature of performing as a teacher in order to achieve identity salience. The final section provides examples where these theories are used to map creative teacher becomings.

\section{Subjectivity, embodiment and identity}

\section{Embodied subjectivity}

Melinda: This term, the stress was full on and I broke out in a rash. I thought I had the chicken pox, but it turned out it was some bacterial infection. My immune system was so run down that it just spread all over my body.

As Melinda illustrates above, teaching is embodied. This means that when analysing emerging teacher identities, it is imperative that paradigms and methodologies are used that take into account the embodied nature of teaching. Neo-materialist understandings of 
embodiment are vital for reconceptualising subjectivity from the unified, rational subject of humanism to the post-humanist, rhizomatic, desiring subject. Neo-materialist, critical posthuman theory is built upon two main platforms: 'the emphasis on the embodied and embedded, relational and affective structure of subjectivity and the grounded and accountable nature of knowledge claims' (Braidotti 2019, 1). This paradigmatic shift from a positivist epistemology to a focus on embodied subjectivity is salient when exploring teacher becomings in the secondary school. It takes into account the transcorporeal agency of (teacher) bodies understood not as 'human', but as 'more-than-human' — where discourse and matter are co-constitutive (Braidotti, 2019). Educational research based on posthuman neo-materialist frameworks provides tools for mapping heterogeneity in non-unitary subjects and how identity construction is modulated by power, discourse, interconnectivity and embodiment.

Braidotti's work, which is inspired by the concepts of Gilles Deleuze and Judith Butler, is generative for making sense of the interview data from ECTs. She views subjectivity as 'a process, made of constant shifts and negotiations between different levels of power and desire, to say, wilful choice and unconscious drives' (Braidotti 2013, 18). Moreover, materialist conceptions of subjectivity, such as Braidotti's, reposition the human among the nonhuman assemblages (such as technology, Teacher Standards and neoliberal discourses). Working with our data and Braidotti's understanding of subjectivity, we seek to explore the physical, psychological, emotional and social interrelations of embodied and embedded teachers. This understanding of subjectivity is exemplified in Mikaela and Jocelyn's description of how their first year of teaching impacted their bodies: 
Mikaela: I would make myself sick trying to do everything I had to do. You can't actually physically do everything you need to do and be an arts teacher at the same time.

Jocelyn: We get sick, but we still have to go in because there's so much that needs doing. We just can't take that time off.

The effects of 'doing everything [Mikaela] had to do' - such as choreographing a classroom, performances, and negotiating complex staff, parent and student relationships - occur on the body. Moreover, being 'sick' appeared to be a normative aspect of the beginning teachers' experiences. Braidotti's conceptualisation of the self exemplifies the importance of a materialist approach to exploring ECTs experiences. 'Materiality' incorporates the idea of power in its formative or constituting effects. This embodied and embedded subjectivity is constantly in flux, always in the process of becoming, and perpetually engaged in dynamic power relations. As Butler (1993) notes, 'Power operates successfully by constituting an object domain, a field of intelligibility, as a taken-for-granted ontology, its material effects are taken as material data or primary givens' (170). For example, the ECTs we interviewed in this study embodied a taken-for-granted field of 'performing arts teacher' that included 'extra-curricular performances' and 'out of school hours' as primary givens:

Melinda: We also do productions and things like that. So, it's running all those things as part of our role. All the extra-curricular stuff.

Melinda accepts the material manifestations of 'stress' such as a 'rash' all over her body, are part of the identity of the performing arts teacher. Materiality is a quality possessed by the physical world that teachers live in. Bodily materialism and the embodied or enfleshed subject is central to our understanding of teacher subjectivity. As Butler (2004) notes: 
'Materiality appears only when its status as contingently constituted through discourse is erased, concealed, covered over. Materiality is the dissimulated effect of power' (251). As we can see from Sophia's comments below, the expectations of the performing arts teacher are 'erased, concealed and covered over' as what 'we do':

Sophia: We had two Sunday rehearsals and then because I direct the show, I'm expected to be at the dance rehearsal for the show, the drama rehearsal, the vocal rehearsal, and I pop in on doing the costuming and other stuff. It's big.

\section{Normative teacher subjectivities}

Subjectivity as understood by Braidotti (following Deleuze), involves the material body 'fully immersed in processes of becoming, in productive relations of power, knowledge and desire. ... an affective, dynamic structure' (Braidotti, 2013, 17). As Braidotti points out, subjectivity is a fluid process of becoming. Melinda describes the process of becoming teacher below in terms of how it impacted her embodied subjectivity:

Melinda: Diet and exercise was important to me when I was at uni but I just don't have the time now. Starting my career has changed a lot about my life. I moved out of home and had my own space but then trying to organise living by myself for the first time, cooking for myself, has resulted in me doing what's easy, maybe not eating because I don't have time. My relationships have changed now that I have to prioritise work. I started a career and then at the same time I grew up. It was all a lot to manage at once. 
As Melinda highlights, the taken-for-granted subjectivity of the teacher is viewed as just part of growing up. She doesn't have time to exercise or eat properly, and her relationships have changed because she now has to 'prioritise work'. Melinda tried to recapture some of her student identity (such as exercising) into her teaching identity but without success:

Melinda: I tried to implement some time to go the gym but then I'd be thinking it takes me 15 mins to get there, 45 mins workout and then 15 mins to get home - I don't have time for that.

This embodied teacher subjectivity is concerning, particularly if the 'concealed' and 'covered over' expectations of teaching are incompatible with physical and mental health and relationships. Melinda elaborates on the work conditions that lead to this change in her life:

Melinda: I find myself getting to school at seven o'clock in the morning and then not leaving until the same time at night. It's a massive 12 hour day every day just trying to get on top of things.

Melinda's embodied experience of teaching was not unique, as Jude and Sophia's comments highlight:

Jude: I run a workshop for the year 11s Tuesday after school. Then during the week, the kids can book out lunch times to rehearse. So I'll supervise during rehearsal.

Sophia: I get to work at between seven and 7:30 most mornings. Some nights, if I leave before seven, that's a bonus. Even after a show, we don't get home till 10:30, 11 
o'clock at night. It's late. If I do get home relatively on time, by the time Icook dinner, do the washing, have a shower and do whatever adult stuff I've got to do.

It is not surprising then that the participants becoming-teacher identities caused relationship issues at home. For example, Sophia's husband was unimpressed with the hours she spent at work.

My work/life balance is not great. My husband does get pissed off at me probably once a term and we have a bit of an explosion because I've not been home.

It is interesting to note that Sophia perceives a teacher identity as being time-consuming - as if this is a given:

Home suffers because I put everything into work. Sometimes we don't have any washing done because my husband's been busy too. We end up having an argument about it. He always says to me, 'You just put work before everything else.' But I think it's a very consuming job and it's really hard not to put it all first.

This sentiment was echoed by other participants:

Jaxon: Although teaching takes up a lot of my time, I think that's the kind of person that I am. I like to commit fully, 100\%. Teaching is rewarding but it's knackering. I think that's something that's tied to the heart of teachers. Because it's a lot of late nights. It's a lot of your free time unpaid, particularly for performing arts teachers. 
As we can see, this teacher subjectivity is a construct that is largely 'concealed' and 'covered over' - even from the participants themselves. Jaxon describes this as being 'tied to the heart of teachers'. Sophia was recently given a permanent position at a school and she reported being determined to 'do things differently' in future. However, having a work/life balance was viewed as not being a good teacher:

I don't have a work/life balance at all. But this year I feel like I've got to this point as well. It's really bad, but I have a bit of like a 'fuck it' attitude. I would never probably have done that three or four years ago 'cause I didn't have a permanent job.

\section{Performing arts teacher identities}

Identity construction involves a negotiation between the teacher and the specific context in which they work. The ECT teachers we interviewed were performing arts teachers: that is dance, drama and music. The participants in every interview group had a similar image of the performing arts teacher that they measured themselves against.

Jude: I feel like there is never a work/life balance. I feel like life as a performing arts teacher just merges. My life becomes my work.

Ross: Certainly, during productions, I'm sure this is the case for everyone, I feel like I never leave [work].

Troublingly, both Jude and Ross conflate "life" with "work" and perceive this as a normative aspect of the 'performing arts teacher' identity: "I'm sure this is the case for everyone" (Ross). Nichols et al. (2017) study outlined the features of the growing literature on early 
career teachers' identities. He noted that teacher identities are not fixed, but rather a fluid becoming related to the interpretation and reinterpretation of experience (see also Sutherland, Howard, and Markauskaite 2010). Max exemplified this interpretation of the performing arts teacher as being different from other teachers:

Being a performing arts teacher can be challenging. The job I had before was not arts based and I found I was having a lot less to do at home. Teaching drama involves a lot of building and writing scripts. This takes a lot of time that I wasn't having to do when I was teaching English, math, science.

Tamara echoed this sentiment, adding that compared with her friends from university, being a drama teacher was an all-consuming profession:

I guess the majority of people who are working, when they leave their job they leave their work. Whereas, we take our work home.

Ross, who has a temporary position teaching drama, explained that the teacher identity was a 'vocational' one:

Teaching degrees are a vocational degree. I actually miss my old job because I never took it home with me. I think my friends have more social time.

For Ross, part of this vocation - or performing arts teacher identity, meant extra-curricular unpaid hours: 
I am the coordinator of the drama and dance festival which is a part of the House Performing Arts Festival. I'm also the choreographer for our musical this year. I assist with the other Arts, like the music nights and the House Film Festival doing supervision and helping backstage.

\section{Desire and agency}

Identity construction for teachers involves human agency, and that in turn requires at least a modicum of control over one's employment. Our study highlights how teacher agency can have a potent impact on teacher becomings. However, this impact is moderated by school culture and desires. As Tamara noted in our discussion on school culture and written and unwritten expectations:

Tamara: I think one [expectation] that's a huge part of our college, is the extracurricular activities that we offer.

Kirsten: How many nights do you think you would be staying back at school during the average week when you're in rehearsal?

Tamara: For extra-curricular ... I'm there on the weekends as well, but in term one it's every night, and then in term two it's only twice. But then, as an effect of doing that, I'm there every night trying to do everything else.

Tamara's remarks highlight that in 21 st century teaching, the desire to conform to the unwritten expectations of her college's culture is not an outside power or force, but a desire that comes from within. These culture values and desires are shaped by neoliberal marketdriven competitive discourses and ideologies (Ball, 2003, 2014; Lambert et al., 2017). Ball, 
following Foucault, theorises that neoliberalism encourages a culture of competitive performativity that pits teachers against one another in a battle to outshine one another and appear productive (2003). This is exemplified in Ashleigh's experience.

Ashleigh: Also, there's a bit of competition in our department where we are all very new and we're trying to look after our own positions, justify our roles and fight for our spot in the curriculum.

As Ashley illustrates, the desire to compete is normalised in contemporary education assemblages, and as Ashley notes, because performing arts teachers are often the only teacher in their subject area in a school, they often find themselves competing for timetable space. This competition is viewed as healthy in a performative educational climate, however, it can be antithetical to a supportive collaborative environment. Compared to other professions, the participants said that they received little support from management.

Amber: I find it interesting because I've worked in other professions where I've had good training and induction. We don't need training in terms of teaching, but we need training on the admin. There's so much admin. We don't know the policies. Each school is different, and things don't run the same way. There's stuff we're supposed to know that we're finding out at the eleventh hour. We have to do something, but no one has told us about it. Then we have to try and fit it in. There's no formal sort of mentoring.

Often participants were satisfied with their pedagogical readiness for teaching upon leaving university, but not for the myriad of other responsibilities the embodied role incurs: 
Jaxon: I felt ready for aspects of teaching, but not others. I still sometimes feel like a fish out of water. It's mainly the admin stuff that makes me feels like this. I found out too late that I was supposed to have downloaded all this stuff and I felt like an idiot.

As a whole, the participants felt prepared to teach in their subject areas upon graduating, but not prepared for the competitive nature of teaching and how this is embodied in a culture of overwork and performativity.

\section{Posthuman subjectivities}

A lack of knowledge of administrative demands is exacerbated by a teacher's interconnectedness with non-human technology, including ICT programs such as SEQTA ${ }^{3}$ :

Ross: There are things I should know, and I don't. Like SEQTA - I knew how to use it but it takes up so much time. The HOLA [Head of Learning Area] said 'Just go and do it'. I was thinking, 'How?' It was expected that I knew what she was talking about.

A lack of teaching experience, unfamiliar technologies, combined with cultural expectations that performing arts teachers would coordinate or supervise extra-curricular activities had an exponential impact on the ECTs:

\footnotetext{
3 SEQTA is described by the private company who owns it as "an all-in-one collaborative teaching and learning ecosystem. By bringing together multiple information sources into one easy-to-use LMS (Learning Management Systems), SEQTA liberates teachers from labour-intensive, disparate and fragmented software or paper-based systems".
} 
Jaxon: When I first started [teaching] there were some things I had no clue about and they've come up in the calendar and someone has come to me and said, 'What have you done about this?' And I've said, 'What?' I didn't even know about it. I do all of this outside my regular teaching load.

Deleuze and Guattari (1987 [2012]) outline the process of becoming, whereby bodies affect other bodies and are transformed within assemblages. Melinda exemplifies how her interaction with other bodies is an integral yet challenging part of an ECTs identity construction:

Melinda: We're so young and inexperienced and I've had some difficult conversations with parents. I wasn't prepared for some of these.

Our research highlights that even so-called 'digital natives' can feel unprepared for the nonhuman technological nature of teaching in the $21^{\text {st }}$ century.

\section{Embodiment and physicality}

The body is central to the process of understanding the ECTs complex interactions with students, staff and parents, as it constitutes a mode of knowing. As Braidotti (2013) notes:

Complexity is the key to understanding the multiple affective layers, complex temporal variables and internally contradictory time and memory lines that frame our embodied existence ... the body is a surface of intensities and an affective field in interaction with others. (25) 
For example, in drama and dance education particularly, ECTs do not merely teach and assess students; they embody or physicalise dancer/actor in the space of the theatre/classroom.

Angela: Behaviour management is still an issue for me. You want to get them [students] on-side and get them to enjoy drama so they continue. You have to build a positive relationship with them to do that. You can't be telling them to stop doing this and that otherwise you won't have numbers.

Jack: Teaching dance - sometimes I feel bi-polar. The extremes. Sometimes I have to be super supportive and other days they have to toe the line.

The effects of physicalising the teacher identity can be significant to participants. The following interview extract elaborates how this embodiment manifests itself in surprising ways:

Ben: I wasn't prepared for parent/teacher interviews. I had no idea what to say in the first one. How do I start? It would have been good to have some mentoring before so that I would know what to expect and what to do. The interviews were five minutes each with music playing like a speed dating service.

Deleuze and Guattari's (1978 [2012]) concept of becoming is salient to this research because it places emphasis on bodily experience, interrelationships and energies within and without 
assemblages. Narelle spoke of these energies when describing her relationship with other staff as a 'vibe':

Narelle: Sometimes, I think that I'm just too young to be in a position where I tell other people what to do and I get that vibe from other teachers. At staff drinks on a Friday, they'll talk across me or talk about things I don't understand from their subject area. And I feel like I don't have anything to add.

Considering this conceptualisation of identity as embodied interrelationships and energies also helps us understand how teachers negotiate complex systems.

Melinda: I need to be a bit careful though depending on who I'm chatting to. If I don't know them very well, I'd need to be careful. I can tell the other drama teacher the truth but others[teachers] you need to be a bit careful and because I'm new, I don't want to say the wrong thing and jeopardise a permanent position.

Melinda's 'careful' identity is influenced by its interconnection with the dominant neoliberal educational climate of competition.

Melinda: I'm responsible for year 12 students and I don't really get any support inside the school.

Narelle: Pre-service training taught us about the pedagogy and content but it's all the other stuff like managing personalities and the different expectations of schools - that wasn't dealt with at all. 
These 'expectations' can be further understood through a consideration of neoliberal subjectivity.

\section{Neoliberal subjectivities}

Neoliberalism moulds 'constituent subjectivities and their relationships' (Doherty $2015,395)$ in the classroom through accountability practices, such as Teacher Standards. Defined as 'an ideology and policy model that emphasizes the value of free market competition' (Smith 2016, 1) neoliberalism functions as a 'metapolicy' (Doherty 2015) of individualism and personal responsibility. Deleuze and Guattari (1987 [2012]) offer an understanding of neoliberalism's 'tactics of domination':

Capitalism arises as a worldwide enterprise of subjectification by constituting an axiomatic of decoded flows. Social subjection, as the correlate of subjectification ... an entire system of machinic enslavement [where] human beings are constituent parts. (505)

If research is to question the taken-for-grantedness of competition, then we must take into account how emotion drives the desires of the embodied teacher. Moreover, the becoming teacher frequently feels insecure about 'doing the right thing' and living up to the Standards.

Jaxon: That's the keyword there - FEELING like a proficient teacher. We need to FEEL like we're a proficient teacher not just tick the Standards off. That's the fish out of water feeling - I'm still feeling insecure and unsure if I'm doing the right thing. 
The data further revealed the ways in which ECT's becomings are affected by dominant neoliberal performative ideologies where energies and attention are 'directed'. Neoliberalism is a form of 'governmentality', that controls 'the way in which the conduct of individuals or groups might be directed' (Foucault, 1977, 341). Rather than being used to support teachers or grow them professionally, the AITSL Standards are utilised by administration as a form of governmentality:

Narelle: Its [the AITSL Standards] just a paperwork thing. It's not really a 'let's support you and try to improve your teaching and alter these lessons to make them incredible and how we can help you with your classroom management and get you feeling like you're a proficient teacher.' It's just a tick a box thing.

The becoming teachers' identities are 'reconfigured as productive economic entrepreneurs of their own lives' (Davies and Bansel 2007, 248-249).

Ross: Because I'm on a contract, I'm doing things so that when it comes to applying for my job again, I can say, 'I do this.' One of my worries as a beginning teacher is remaining employed.

Being on short-term employment contracts acts as a form of governmentality for ECTs. To govern through job insecurity, 'is to structure the possible field of action of others' (Foucault, 1977, 341). Ball (2003), drawing upon Foucault, asserts that education systems are governed by the performativity principle through the corporatisation and marketisation of schools. This performative culture was echoed in our research findings. Amber, an independent school teacher, describes it this way: 
Amber: At my last school, we had a nurture program. We'd go to the meeting and instead of checking in with everyone, the woman told us we were getting two review lessons and that she was coming into watch us teach. We also had student surveys that the kids completed about how we were going. Just for new teachers. It was so much extra pressure. The intention's there but the reality is more pressure.

As Amber's comments highlight, even institutional measures introduced to support ECTs such as 'nurture programs' are used as another form of governmentality by administration in competitive neoliberal school cultures.

Surveillance and subjectivity

Theorists who apply Foucault's theory of governance to education stress that teachers are enmeshed in a matrix of power relations (Ball 2012; Besley and Peters 2008; Peters 2015). Teachers are controlled through what Foucault (1977) would describe as the constant surveillance (panopticism) of testing and ranking in schools:

The power relations, not above but inside the very texture of the multiplicity, as discreetly as possible ... anonymous instruments of power, coextensive with the multiplicity that they regiment, such as hierarchical surveillance, continuous registration, perpetual assessment and classification. (1977, 220) 
This constant surveillance can be seen in the managerial implementation of the AITSL Standards. As Melinda notes, the Standards are used in schools to judge, rather than support ECTs:

Melinda: I've had an observation lesson where all they did was record everything I said and did and didn't actually give me any feedback.

This is one manifestation of hyper-surveillance. Corporate discourses of performance, competition and accountability contribute to the hyper-surveillance of teachers.

The ECTs report enormous pressure to perform and, therefore, choices for students, such as which subjects to study, are made on the basis of getting better marks in exams. For the schools the ECTs worked at the only reliable 'measure of quality' is statistical data such as year 12 exam results. As we can see from Melinda's experiences with the Careers Advisor, ‘neoliberalism LOVES quantitative reductionism' (Lather 2012, 1023).

Melinda: Our Careers Advisor doesn't support drama either. When kids are going into upper school and are trying to decide what marks they need to get into university, the Career Advisor is telling them not to do drama. 'You won't have a career in it. Do science instead'. A change of culture is needed and that's hard.

Jaxon: And dance is even worse. If drama is thought of like that then dance is the arse end. Culture change is needed.

As a result of this 'metric mania' (Paulos 2010, 3) subjects such as drama and dance, which are not readily quantifiable, end up at the 'arse end' of the curriculum hierarchy. Yet how do 
these neoliberal educational cultures and embodied subjectivities affect ECTs sense of teacher identity salience?

\section{Performing Teacher}

Butler's (2004) theory of performativity emphasises the social construction of subjectivities and their contingent and discursive nature. She argues that identity is discursively constituted though a matrix of constantly changing norms that constrain 'what we can be' $(2004,57)$.

This is useful for understanding the multiple and contradictory discourses that shape ECTs becomings. It also challenges the 'common sense' notion of progressing through Professional Standards and opens up a multitude of creative possibilities. Butler's theory of gender performativity illustrates how subjectivity is shaped:

If gender is a kind of doing, an incessant activity performed, in part, without one's knowing and without one's willing, it is not for that reason automatic or mechanical. On the contrary, it is a practice of improvisation within a scene of constraint. (Butler 2004, 4)

We incorporate Judith Butler's theory of performativity to explore how ECTs becomings are continually fashioned through repetition and mimicry within hegemonic discourse. Jaxon highlights how ECTs identity construction is performative in that they 'fake it' (mimicry) until they 'feel' like a teacher (identity) through 'pretending' (repetitive performative acts). 
Jaxon: I still sometimes feel like a fish out of water... [The Standards] will provide the steps to get us there, however, whether we feel it ourselves is another thing... The thing is - it's whether we feel proficient. You have to fake it to you make it. Pretend you know what you're doing.

When discussing their own proficiency, as defined by the AITSL standards, Amber and Laura noted,

Amber: The new graduate program was supposed to help us progress through the AITSL standards but it was about ticking off the boxes rather than checking in with how everyone was going. I have to get my HOD to come and watch me.

Laura: I'm the only dance teacher, so if I don't do it, it doesn't get done. There's no one to help so I feel like I'm constantly trying to climb this mountain that's just huge.

Each of these identities was performed successfully, or unsuccessfully in relation to other identities and forces. The self is understood and performed differently depending upon the discursive environment (Butler 2004) as we can see with Amber having to perform for her HOD. This performance of proficient teacher is contradictory and in a state of flux. Laura performed proficient teacher 'so if I don't do it, it doesn't get done', but felt inadequate to 'climb this mountain' without help. Subjectivity here is constructed through discourse and is essentially ambiguous, embodied, and rhizomatic. 
All of the aforementioned factors such as stress, lack of support, excessive workloads and a failure to achieve identity salience contribute to a high attrition rate amongst early career secondary teachers. Ross explains how this played out in his school.

Ross: Last year, I took over from the drama teacher who left. There's always someone leaving. The senior school teacher left and all of us were part time. There was a graduate first year out teacher and she went. And when she was making plans to go, one of the things she said was that she felt there wasn't enough gratitude and appreciation.

The situation at Ross' school paints a bleak picture for early career teachers, however, the teachers in our study found creative lives of flight from the discourse of crisis.

\section{Becoming a creative teacher}

The theories of Butler, Deleuze and Guattari offer frameworks and vocabularies for understanding mapping creative becomings. Our research found that the transcorporeal embodiment of the performing arts teacher for ECTs has a profound impact on their becomings. Narelle described the most rewarding ECT experiences in this way:

Narelle: They hadn't had a drama club in a couple of years and starting it up with Amber and having 40 kids sign up from day one was amazing. Those moments when you don't expect it, but you see how much you've made a difference and they appreciate it.

On becoming, Deleuze and Guattari state that 'Becoming and multiplicity are the same thing' (1978 [2012], 275). In the context of the arts, linking these two developmental forces 
highlights the way that drama offers teachers this multiplicity of dimensions. Thus, we were able to see the intersection of the teachers, the embodied role, and the space of the performing arts classroom itself, as energies and affects that transform one another.

Jaxon: I really like all the positive feedback from the kids about how I'm going which is always good for the ego but it's good to know that I've made the right choice in becoming a teacher. When we finished the musical, the students did a little slide show on the final night to show their appreciation of the teachers involved. When my picture flashed up, all the kids cheered, and they appreciated the time I'd put in for the production. The relationships with the students - that's the best part.

It is also important to understand that this multiplicity occurs in particular spaces. Deleuze and Guattari (1987 [2012]) distinguish between two types of spaces: smooth space and striated space. Smooth space is heterogeneous, creative and flexible, whereas striated space is homogenous and controlled (523-551). Linking space and embodiment in this research because it highlights how smooth space and creative energy can assist ECTs to persist through the difficulties of teaching.

Ben: Running around with year sevens is inherently fun. And they all love it and they've got no social inhibitions. They're not embarrassed by performing in front of the opposite sex yet. So, yeah, if I had no year sevens, I would be miserable. I need my year sevens.

As we have seen, Deleuze offers a range of concepts such as becoming, rhizomes and desire. The Deleuzian notion of desire as a force incorporates drives and intensities that produce new becomings. This notion of desire works through the stories of the teachers, introducing our 
own notion of 'desiring creativity', to map out some of the 'doings' of desire, for instance, dynamics of creativity as a means of surviving teaching.

Maya: I have some amazing relationships at the school - especially the other drama and dance teachers. It can be a really fun, creative environment and just being able to walk into another drama class and watch their stuff and say 'Hey, can you come in and watch.' We try to do this as much as we can but it's hard finding time. We do this with the dance teacher to as there's so much cross over.

The embedding of ECTs in a collegial environment enabled these teachers to explore multiple possible selves and perform passionate and energetic identities.

Melinda: I got this job because I was a drama teacher. The staff said, 'We need someone who has passion and energy in our English Department.' The kids pick up on this and say, 'You actually smile at us, you're so happy, we don't want you to go.' Where's that reflected in the standards?

Yet these qualities are not recognised in the Standards.

Ross: The creativity as a performing arts teacher and extra-curricular is not reflected in these standards. We love doing these things, but we're expected to do everything else.

The assemblage of bodies, classrooms and neoliberal discourses are both enabling and constraining forces on teacher becomings. 


\section{Conclusion}

In the face of alarming rates of teacher attrition, the task of supporting and retaining beginning teachers has received considerable international attention in recent years. This study set out to explore how ECTs construct identities in relation to mandated Professional Standards. Specifically, we considered how embodied teacher identities are formed in secondary schools and how the Standards are being used to support ECTs develop identity salience.

Combining Braidotti, Deleuze, Foucault and Butler's concepts opens up new possibilities of conceiving ECT subjectivity. These neo-materialist post-humanist theories of embodiment, materiality and desire illuminate the often taken-for-granted power relations in and between bodies in schools. This study found that ECT identity salience can be constrained through the pervasive influence of performative neoliberalism that requires excessive work-loads, high levels of stress and insecure employment conditions in order to remain competitive in the teacher 'market'. Finding themselves under constant surveillance, performing arts teachers often find themselves working non-paid extra-curricular hours to retain their positions. Many of them leave.

Our research reveals the multiple and often problematic discourses that surround institutionally mandated Standards. Even measures introduced to support ECTs such as mentor and nurture programs are used as another form of governmentality by administration in competitive neoliberal school cultures. This governmentality and its associated surveillance are internalised by human subjects through a culture of competitive performativity where teachers attempt to outdo one another in order to secure stable 
employment and maintain student numbers in optional classes. Most troublingly perhaps, is that our participants felt completely powerless to achieve even a modicum of control over their unstable employment circumstances. Time and time again we heard stories of ECTs who worked 70-hour weeks in short term contracts. They 'performed teacher' with the energy and enthusiasm of a young person who has studied for four years at university and is excited about their new career. In their first year of teaching they taught with passion and knowlege of content and pedagogy, built outstanding relationships with students, navigated unfamiliar ICT systems and directed mammoth productions - only to find themselves unemployed by the end of the year or term. Perhaps it is understandable that many of our 'best and brightest' abandon teaching before they feel secure with their new identities.

Yet creativity and collaboration between performing arts teachers can facilitate teacher identity salience, including creative, energetic and passionate becomings. This support leads to generative teaching that resists hegemonic competitive identites in the current neoliberal educational assemblage. Early career teachers can find the embodiment of performing arts teacher subjectivities a powerfully transformative experience if they are able to find lines of flight from capitalist governmentality. As one teacher, sharing her experiences, insightfully concluded:

Amber: The Standards say what you have to do but the relationship stuff and the passion isn't reflected. And that's what drama teachers do best. 


\section{Disclosure Statement}

No potential conflict of interest was reported by the authors. 


\section{References:}

Ado, Kathryn. 2013. “Action Research: Professional Development to Help Support and Retain Early Career Teachers." Educational Action Research 21 (2): 131-46. doi:10.1080/09650792.2013.789701.

AITSL. 2011. Australian Professional Standards for Teachers Australian Institute for Teaching and School Leadership: https://www.aitsl.edu.au/teach/standards

Ball, Stephen. J. 2003. "The teacher's soul and the terrors of performativity." Journal of Education Policy, 18(2), 215-228.

Ball, Stephen. J. 2012. "Education reform as social barberism: Economism and the end of authenticity." Praxis Educativa, 7(1), 33-52.

Bandura, Albert. 1997. "Self-Efficacy." Harvard Mental Health Letter 13 (9): 4.

Besley, Tina. A. C., and Michael A Peters. 2008. Subjectivity and truth: Foucault, education and culture of the self. New York: Peter Lang.

Bong, Mimi, and Einar M. Skaalvik. 2003. “Academic Self-Concept and Self-Efficacy: How Different Are They Really?” Educational Psychology Review 15 (1): 1-40. doi:10.1023/A:1021302408382.

Borman, Geoffrey D. and N. Maritza Dowling. 2008. "Teacher Attrition and Retention: A Meta-Analytic and Narrative Review of the Research.” Review of Educational Research 78 (3): 367-409. doi:10.3102/0034654308321455.

Braidotti, Rosi. 2013. The posthuman. London: Polity Press.

Braidotti, Rosi. 2019. Posthuman Knowledge. Medford, MA: Polity.

Butler, Judith. P. 1990. Gender trouble. New York: Routledge. 
Butler, Judith. P. 2004. Undoing gender. New York: Routledge.

Caza, Brianna Barker, Sherry Moss, and Heather Vough. 2018. "From Synchronizing to

Harmonizing: The Process of Authenticating Multiple Work

Identities." Administrative Science Quarterly 63 (4): 703-45.

doi:10.1177/0001839217733972.

Chiva, Ricardo. 2017. "The Learning Organization and the Level of Consciousness." The Learning Organization 24 (3): 150-58. doi:10.1108/TLO-11-2016-0074.

Clandinin, D Jean, Julie Long, Lee Schaefer, C. Aiden Downey, Pam Steeves, Elizer Pinnegar, Sue McKenzie Robblee, Sheri Wnu. 2015. "Early career teacher attrition: Intentions of teachers beginning." Teaching Education, 26(1), 1-1.

Clarke, Matthew, and Alex Moore, (2013). Professional Standards, teacher identities and an ethics of singularity. Cambridge Journal of Education, 43(4), 487-500 https://doi.org/10.1080/0305764X.2013.819070

Davies, Bronwyn, and Bansel, Peter. 2007. Neoliberalism and education. International Journal of Qualitative Studies in Educaiton, 20(3), 247-259.

Deleuze, Gilles. 1994 (2012). Difference and repetition. London: Continuum.

Deleuze, Gilles, and Felix Guattari. 1977. Anti-oedipus: Capitalism and schizophrenia. New York: Viking.

Deleuze, Gilles, and Felix Guattari. 1987 (2012). A thousand plateaus. London: Continuum International Publishing Group.

Doherty, Catherine. 2015. "Tracking the neoliberal juggernaut: A virtual edition." Critical Studies in Education, 56(3), 395-401.

Down, Barry. 2009. "Schooling, productivity and the enterprising self: Beyond market values." Critical Studies in Education, 50(11), 51-64. 
Dupriez, Vincent, Bernard Delvaux, and Sandrine Lothaire. 2016. Teacher shortage and attrition: Why do they leave? British Educational Research Journal, 42(1), 21-39. doi:10.1002/berj.3193

Djonko-Moore, Cara M. 2016. An exploration of teacher attrition and mobility in high poverty racially segregated schools. "Race Ethnicity and Education." 19(5), 1063 1087. doi:10.1080/13613324.2015.1013458

Ericsson, K. Anders, Ralf Th Krampe, and Clemens Tesch-Romer. 1993. "The Role of Deliberate Practice in the Acquisition of Expert Performance." Psychological Review 100 (3): 363.

Ericsson, K. Anders. 2013. “Training History, Deliberate Practice and Elite Sports Performance: An Analysis in Response to Tucker and Collins Review - What Makes Champions?(Editorial).” British Journal of Sports Medicine47 Foldal, Vegard, Eva Langvik, and Ingvild Saksvik-Lehouillier. 2016. "Dispositional Factors and Work Mastery among Shift Workers.” Chronobiology International 33 (6): 650-52. doi:10.3109/07420528.2016.1167718. (9): 533.

Foucault, Michel. 1977. Discipline and punish: The birth of the prison (trans. A. Sheridan). London: Penguin.

Gable, Shelly L, and Jonathan Haidt. 2005. "What (and Why) Is Positive Psychology?” Review of General Psychology 9 (2): 103-10. doi:10.1037/10892680.9.2.103.

Giddens, Anthony. 1991. Modernity and Self-Identity : Self and Society in the Late Modern Age. Cambridge, U.K.: Polity Press in association with Basil Blackwell. 
Glickman, Carl D, and Roy T Tamashiro. 1982. "A Comparison of First-Year, Fifth-Year, and Former Teachers on Efficacy, Ego Development, and Problem Solving." Psychology in the Schools 19 (4): 558-62. doi:10.1002/15206807(198210)19:4<558::AID-PITS2310190426>3.0.CO;2-F.

Golden, Lonnie. Julia R Henley and Susan Lambert. 2013. Work Flexibility: A Contributor to Happiness, The Cost of Millennial Retention Study, https://theconversation.com/englands-school-system-is-in-crisis-could-labours-nationaleducation-service-be-the-solution-111555

Guskey, Thomas R, and Perry D Passaro. 1994. "Teacher Efficacy: A Study of Construct Dimensions." American Educational Research Journal 31 (3). doi:10.2307/1163230. Hackman, Michelle an Eric Morath. 2018. "Teachers quit jobs at highest rate on record." The Wall Stree Journal. December 28, 2018. https://www.wsj.com/articles/teachers-quitjobs-at-highest-rate-on-record-11545993052

Jha AP, Stanley E A, Kiyonaga A, Wong L, and Gelfand L. 2010. "Examining the Protective Effects of Mindfulness Training on Working Memory Capacity and Affective Experience.” Emotion (Washington, D.C.) 10 (1): 54-64. doi:10.1037/a0018438.

Johnson, Bruce, and Barry Down. 2013. "Critically Re-Conceptualising Early Career Teacher Resilience.” Discourse 34 (5): 703-.

Lambert, Kirsten, Peter R Wright, Jan Currie, and Robin Pascoe. 2015. “Data-Driven Performativity: Neoliberalism's Impact on Drama Education in Western Australian Secondary Schools.” Review of Education, Pedagogy \& Cultural Studies37 (5): 46075.

Lambert, Kirsten., Peter R Wright, Robin Pascoe and Jan Currie. 2017. "Desiring machines and nomad spaces: Neoliberalism, performativity and becoming in senior secondary 
drama classrooms." Discourse: Studies in the Cultural Politics of Education, 1-12. doi:10.1080/01596306.2015.1074429

Lather, Patti. (2012). "The ruins of neo-liberalism and the construction of a new (scientific) subjectivity." Cultural Studies of Science Education, 7(1), 1021-1025.

Loughland, Tony, and Neville Ellis. 2016. "A Common Language? The Use of Teaching Standards in the Assessment of Professional Experience : Teacher Education Students' Perceptions.” Australian Journal of Teacher Education 41 (7): 56-69.

Lieberman, Ann, and Desiree Pointer Mace. 2010. "Making Practice Public: Teacher Learning in the 21st Century." Journal of Teacher Education 61 (1-2): 77-88. doi:10.1177/0022487109347319.

Long, Julie S, Sue McKenzie-Robblee, Lee Schaefer, Pam Steeves, Sheri Wnuk, Eliza Pinnegar, and D Jean Clandinin. 2012. "Literature Review on Induction and Mentoring Related to Early Career Teacher Attrition and Retention.” Mentoring \& Tutoring 20 (1): 7-7.

Malmberg, Lars-Erik, Hazel Hagger, and Sophie Webster. 2014. “Teachers' SituationSpecific Mastery Experiences: Teacher, Student Group and Lesson Effects.(Author Abstract)." European Journal of Psychology of Education29 (3): 429.

Martin, Linda E, and Thalia M Mulvihill. 2016. "Examining Teacher Attrition and Other Related Issues: A Conversation with Dr. D. Ray Reutzel.” Teacher Educator 51 (2): 91-96.

Mason, Shannon and Cristina Poyatos Matas. 2015. "Teacher Attrition and Retention Research in Australia: Towards a New Theoretical Framework." Australian Journal of Teacher Education, 40(11). Retrieved from http://ro.ecu.edu.au/ajte/vol40/iss11/3 
Mazzei, Lisa A. 2013. "Materialist Mappings of Knowing in Being: Researchers Constituted in the Production of Knowledge." Gender and Education 25 (6): 776-76. doi:10.1080/09540253.2013.824072.

McDowall, Almuth, and Gail Kinman. 2017. "The New Nowhere Land? A Research and Practice Agenda for the ‘Always on' Culture.” Journal of Organizational Effectiveness: People and Performance4 (3): 256-66. doi:10.1108/JOEPP-05-20170045.

McNally, Jim, Allan Blake, Brian Corbin, and Peter Gray. 2008. "Finding an Identity and Meeting a Standard: Connecting the Conflicting in Teacher Induction.” Journal of Education Policy 23 (3): 287-98.

McPhee, Peter. and Glenn C. Savage. 2014. "A Year in, Pyne's radical education changes have ignored evidence." The Conversation August 28, 2014. http://theconversation.com/a-year-in-pynes-radical-education-changes-have-ignoredevidence-30786

Nichols, Sharon L, Paul A Schutz, Kelly Rodgers, and Kimberly Bilica. 2016. "Early Career Teachers' Emotion and Emerging Teacher Identities.” Teachers and Teaching 1-16: 1-16. doi:10.1080/13540602.2016.1211099.

Nichols, Sharon L, Paul A Schutz, Kelly Rodgers, and Kimberly Bilica. 2017. "Early Career Teachers' Emotion and Emerging Teacher Identities." Teachers and Teaching: Theory and Practice23 (4): 406-21.

Paulos, J. Allen. 2010. "Metric mania." New York Times Magazine, May 16, 2010. https://www.nytimes.com/2010/05/16/magazine/16FOB-WWLN-t.html

Organ, Dennis. W. 1988. Issues in organization and management series. Organizational citizenship behavior: The good soldier syndrome. Lexington, MA, England: Lexington Books/D. C. Heath and Com. 
Peters, Michael. A. 2015. "Postcolonial biopolitics in the empire of capital: Lines of Foucauldian inquiry in educational studies." Educacao Unisinos, 19(1), 88-100.

Pyne, Christopher. 2014. "Spreading opportunity and staying competitive - why we need the higher education reform package" [Press release] https://www.npc.org.au/speakers/the-hon-christopher-pyne-mp/

Rippon, Janice, and Margaret Martin. 2006. "Call Me Teacher: The Quest of New Teachers." Teachers and Teaching 12 (3): 305-24.

Salas-Vallina Andrés, Joaquin Alegre, and Fernández Rafael. 2017. “Organizational Learning Capability and Organizational Citizenship Behaviour in the Health Sector: Examining the Role of Happiness at Work from a Gender Perspective.” The International Journal of Health Planning and Management32 (2): 159. doi:10.1002/hpm.2363.

Schawbel, Dan. 2013. "Five Key Findings About Millennial Workers." The Globe and Mail (Index-Only) B.12: 12.

Sherman, Arie, and Tal Shavit. 2018. "The Thrill of Creative Effort at Work: An Empirical Study on Work, Creative Effort and Well-Being.” Journal of Happiness Studies 19 (7): 2049-69. doi:10.1007/s10902-017-9910-х.

Slawson, Nicola and Adams, Richard. 2018 "Teachers to be offered year's paid sabbatical to improve retention." The Guardian. May 4, 2018.

May)https://www.theguardian.com/politics/2018/may/04/teachers-to-be-offeredyears-paid-sabbatical-to-improve-retention

Smethem, Lindsey. 2007. "Retention and Intention in Teaching Careers: Will the New Generation Stay?” Teachers and Teaching: Theory and Practice 13 (5): 465-80. doi:10.1080/13540600701561661.

Smith, Nicola. 2016. "Neoliberalism". In Editors of Encyclopaedia Britannica (Eds.), Encyclopaedia Britannica. UK: School and Library Subscribers. 
Stroud, Gabbie. 2018. Teacher: one woman's struggle to keep the heart in teaching. Australia: Allen and Unwin.

Sutherland, Louise, Sarah Howard, and Lina Markauskaite. 2010. "Professional Identity Creation: Examining the Development of Beginning Preservice Teachers' Understanding of Their Work As Teachers." Teaching and Teacher Education 26 (3): 455-65. doi:10.1016/j.tate.2009.06.006.

Tapper, James. 2018. "Burned out: why are so many teachers quitting or off sick with stress?" The Guardian, May 13, 2018. https://www.theguardian.com/education/2018/may/13/teacher-burnout-shortagesrecruitment-problems-budget-cuts

Tickle, Louise. 2018. "'Every lesson is a battle!': Why teachers are lining up to leave." The Guardian, April 10, 2018.

https://www.theguardian.com/education/2018/apr/10/lesson-battle-why-teacherslining-up-leave

Trent. 2015. "The Gendered, Hierarchical Construction of Teacher Identities: Exploring the Male Primary School Teacher Voice in Hong Kong.” Journal of Education Policy 30 (4): 500-517. doi:10.1080/02680939.2014.973456.

Tuytens, Melissa, and Geert Devos. 2010. “The Influence of School Leadership on Teachers' Perception of Teacher Evaluation Policy.” Educational Studies 36 (5): 521-21.

Waters, Jaime. 2015. “Snowball Sampling: A Cautionary Tale Involving a Study of Older Drug Users.” International Journal of Social Research Methodology18 (4): 367-80. doi:10.1080/13645579.2014.953316.

Wright, Chris F, Nick Wailes, Greg J Bamber, and Russell D Lansbury. 2017. “Beyond National Systems, Towards a ‘Gig Economy’? A Research Agenda for International 
and Comparative Employment Relations." Employee Responsibilities and Rights Journal 29 (4): 247-57. doi:10.1007/s10672-017-9308-2.

Zwick, Austin. 2018. "Welcome to the Gig Economy: Neoliberal Industrial Relations and the Case of Uber." Geojournal 83 (4): 679-91. doi:10.1007/s10708-017-9793-8. 